\title{
Carta ao Editor - Viscosuplementação - Rezende MU, Campos GC. Rev Bras Ortop 2012;47(2):160-164
}

\author{
Iberê Pereira Datti ${ }^{1 \odot}$ \\ ${ }^{1}$ Grupo de Cirurgia de Joelho, Clínica de Ortopedia e Traumatologia, \\ Hospital do Servidor Público Municipal, São Paulo, SP, Brasil
}

Rev Bras Ortop 2021;56(2)(2):271.

A viscossuplementação com ácido hialurônico é um tratamento bastante utilizado em doenças articulares degenerativas. Vários artigos mostram que o peso molecular do ácido hialurônico adotado é relevante para a melhora duradoura dos sintomas, já que a molécula de alto peso molecular tem melhor desempenho na avaliação em longo prazo. Nesse cenário, o médico precisa saber o peso molecular do produto escolhido para definir as expectativas e determinar a melhor opção para cada caso.

Infelizmente, é comum haver dificuldade em saber o peso molecular de cada produto comercializado. Em uma atualização publicada pela Revista Brasileira de Ortopedia (Viscosuplementação - Rezende MU, Campos GC. Rev Bras Ortop. 2012; 47(2):160-164), ${ }^{1}$ o Durolane ${ }^{\circledR}$ é considerado um produto de peso molecular intermediário (entre 1 e $1,8 \times 10^{6} \mathrm{Da}$ ). No entanto, isso não parece ser verdade, já que não está de acordo com o Institut national d'excellence en santé et services sociaux
Endereço para correspondência Iberê Pereira Datti, Hospital do Servidor Público Municipal, Rua Castro Alves, 60, Aclimação, São Paulo, SP, 01532-000, Brasil (e-mail: iberedatti@hotmail.com).

(INESSS, Canadá), equivalente à Agência Nacional de Vigilância Sanitária (ANVISA) no Brasil, que caracteriza o Durolane ${ }^{\circledR}$ como um ácido hialurônico de peso molecular muito alto (acima de $100 \times 10^{6} \mathrm{Da}$ ) (Agence d'évaluation des technologies et des modes d'intervention en santé, AETMIS. Viscosupplementation for the Treatment of Osteoarthritis of the Knee. Report prepared for AETMIS by Pierre Dagenais and Alicia Framarin (AETMIS 07-06). Montréal: AETMIS, 2007.).

Não consegui encontrar informações sobre Bioventus ${ }^{\circledR}$. Acredito que essa informação deveria ser revista.

\section{Referência}

1 de Rezende MU, de Campos GC. Viscosuplementação. Rev Bras Ortop 2015;47(02):160-164
DOI https://doi.org/

10.1055/s-0041-1728704. ISSN 0102-3616.
(C) 2021. Sociedade Brasileira de Ortopedia e Traumatologia. All rights reserved.

This is an open access article published by Thieme under the terms of the Creative Commons Attribution-NonDerivative-NonCommercial-License, permitting copying and reproduction so long as the original work is given appropriate credit. Contents may not be used for commercial purposes, or adapted, remixed, transformed or built upon. (https://creativecommons.org/ licenses/by-nc-nd/4.0/)

Thieme Revinter Publicações Ltda., Rua do Matoso 170, Rio de Janeiro, RJ, CEP 20270-135, Brazil 